\title{
ISTINITOST KNJIŽEVNOSTI U KNJIŽEVNOISTORIJSKOM POSTUPKU FRANKA MORETIJA
}

Rad se zasniva na filozofskim teorijama istine (teorije korespondencije, koherencije i evidencije) i njima srodnim modelima istinitosti književnosti (mimetički, etički, epistemološki, figurativni, i model autentičnosti) kako bi se analizirao književnoteorijski i književnoistorijski rad Franka Moretija. U prvom delu rada razmatra se opšta problematika teorije književne istorije i uspostavlja pojmovna osnova za dalju analizu. Problematizuju se minimalni kriteriji za konstituisanje književne istorije i daje sažeta analiza paradigmi klasičnih modela književne istorije (paradigma razvoja, funkcionalna paradigma, teorija ciklične istorije) i njihovog odnosa prema istinitosti književnosti. Drugi deo rada razmatra problem najnovije, narativne paradigme, i shvatanje istorije iz perspektive reprezentativnih poststrukturalističkih teoretičara Rolana Barta i Hejdena Vajta. Primenom usvojenog teorijskog modela, ispostavlja se da narativna paradigma negira mogućnost dolaska do istine putem istoriografskog rada, pa tako i relativizuje istinitost književnosti. U trećem delu razmatra se Moretijev rad u kontekstu prethodno naznačenih paradigmi teorije književne istorije. Pregledom i analizom Moretijevih teorijskih i poetičkih tekstova, analiziraju se ključne postavke sa stanovišta praktičnog književnoistoriografskog rada i njegovih implikacija po istinitost književnosti. Pažljiviji pogled na metodologiju otkriva da njegov rad samo naizgled ispunjava minimalne kriterije za konstituisanje književne istorije. Štaviše, Moreti se približava narativnoj paradigmi utoliko što drukčijim sredstvima konstruiše jednu viziju književnosti koja na kraju ipak ne poseduje autonomno značenje niti je nosilac istine. Iako Moretijev rad predstavlja svojevrsni pokušaj rešavanja metodološke krize književne istorije, njegov kvantitativni formalizam samo maskira relativizam.

Ključne reči: Moreti; operacionalizacija; istorija književnosti; književne teorije; teorija književne istorije; teorije istine; digitalna humanistika; kvantitativni formalizam;

*_stefan.alidini@gmail.com 


\section{I}

\section{Opšti problemi teorije književne istorije}

Obično se smatra da je istorija književnosti doživela svoju najozbiljniju krizu već polovinom dvadesetog veka, naročito iz perspektive savremenih teorijskih strujanja, i poststrukturalističkih teorija koje su tada počinjale svoj misaoni život. Poststrukturalistička kritika nije se ograničavala samo na fenomen književne istorije - mada to jeste bilo područje na kom se efekat novih teorijskih strujanja najpre odrazio - već i na prirodu istoričnosti same, pa otud i na sveukupni smisao istorijskog, i mesto istorijskog znanja u korpusu obrazovanosti. ${ }^{1}$ Ključna pozicija vrednosti istorijskog znanja iz perspektive poststrukturalizma napadana je spregom različitih argumenata, od kojih su neki pripadali samoj književnoj istoriji i metodološkim raspravama koje su se odvijale unutar same discipline. Rolan Bart (Barthes) i Hejden Vajt (White), uz još nekolicinu drugih teoretičara, imali su ključni uticaj na promenu paradigme u shvatanju i vrednovanju književne istorije.

Ovaj rad zasniva se na specifičnoj tački gledišta, jer pokušava da skicira modele razumevanja književnosti, preciznije, razumevanje istinitosti književnosti, spram ponuđenih paradigmi književne istorije. Otud, on počiva na pretpostavci da svaki razrađen koncept književne istorije počiva na nekakvim principima i shvatanju književnosti. No, iako je ovakva vrsta analize možda interesantnija kao organon za bolje razumevanje klasičnih, devetnaestovekovnih koncepcija književne istorije, fokus istraživanja biće na savremenim problemima, i pitanju istinitosti književnosti koja stoji iza istoriografske i teorijske koncepcije Franka Moretija (Moretti), koji slovi za jednog od najpoznatijih i najpopularnijih književnih kritičara današnjice. ${ }^{2}$ No, da bi se razumeo smisao i konačni opseg savremenih problematizacija, neophodno je barem skicirati mogućnosti „klasične“ književne istorije, i njene domete u okviru onih primera koji su nam dostupni, pa tek onda pristupiti problemima savremene teorije.

1 Iako se argumentacija ponuđena tokom rada može lako proširiti na istoriju kao disciplinu, ovde ćemo se zadržati samo na onim aspektima problema koji su naročito simptomatični za probleme savremene književne istorije.

2 Putokaz i osnovno teorijsko uporište za izvođenje naše analize zasniva se na teorijama istine (teorije korespondencije, koherencije, evidencije) i pet modela istine književnosti (mimetički, epistemološki, etički, figurativni i model autentičnosti) koje su sistematizovali Piter Lamark (Lamarque) i Stajn Olsen (Olsen), a koje je kod nas u studiji Istina i poetika razradio i problematizovao Kornelije Kvas. 
Uslovno rečeno, može se reći da postoje tri minimalna uslova za konstituisanje (književne) istorije: 1) određen vremenski period, 2) definisan kriterij za selekciju građe i 3 ) formira nekakav koherentan poredak. $\mathrm{Na}$ taj način, jedna književna istorija se može konstituisati i kao analitička i kao sintetička, i kao problemska i kao suma naučnog znanja, ali samo onda kada njen rezultat počiva na temeljima koji se mogu argumentovano razložiti i braniti. Koherencija celine istorije počiva na valjanosti odabranog vremenskog opsega, i kriterija selekcije koji je tom opsegu prirođen - posredi mogu biti vremenske, epohalne, formalne, žanrovske, faktografske, narativne ili neke druge odlike. Tek ukoliko su ova dva kriterija u saglasju, moguće je iz njih izvesti nekakav poredak. Bezgranična ,istorija svega“, ili sveukupna istorija formi, ili pak ,globalna“ istorija bilo kog fenomena, ubrzo bi se raspale pod težinom i obimom svojih zadataka, te bi i oni zaključci do kojih bi mogle doći bili upitni upravo zbog nedostatka celovitog procesa rezonovanja. Isto tako i specifična istorija određene pojave, ukoliko se prati u lošem vremenskom okviru, sa loše odabranim primerima, takođe ne može izroditi smisaonu istoriju književnosti. Većina stereotipa o pozitivističkim istorijama književnosti i potiče od loših primera istorija koje su gomilale nizove ,pisaca i dela“ bez unutrašnje povezanosti. Drugim rečima, čak i ovi primeri svedoče da kriteriji klasično shvaćene istorije književnosti počivaju na pretpostavci o razrađenom i koherentnom razumevanju književnog procesa.

Kada se, pak, pažnja usmeri na modele i vrste razumevanja književnosti, možemo govoriti o paradigmama književne istorije. ${ }^{3}$ Ideja razvoja dugo je služila kao temeljni pojam organizacije istorijske građe, kako pokazuju i Ulig (2010: 31) i Lešić (1985: 25-64). Razvoj je sam po sebi koncept romantičarskih shvatanja o umetnosti, o organicističkoj prirodi kako umetničkih formi, tako i individualnih pesničkih genija, sve do velikih celina poput epoha ili nacionalnih književnosti, ${ }^{4}$ i podrazumeva razlo-

3 Paradigma, to jest promena paradigme je ovde shvaćena u kontekstu koji joj je dao Tomas Kun (Kuhn), definišući je kao korenitu promenu osnovnih pretpostavki i prakse u nekoj naučnoj disciplini.

$4 \quad$ U svom osvrtu na paradigme književne istorije, Klaus Ulig razdvaja ideju radikalne neponovljivosti (u smislu subjektivističkih i impresionističkih viđenja književne istorije, poput Kročeovog (Croce) shvatanja) od same paradigme razvoja. Sa druge strane, Zdenko Lešić u svom pregledu svaku od funkcionalizacija paradigme razvoja tretira kao zasebnu ideju u okviru duhovne klime devetnaestog stoleća, maltene i ne spominjući paradigmu cikličnosti. To je posledica drukčijeg pristupa problemu, jer je Lešić 
žan i zakonomeran progresivni hod. Na taj način, društvo, duh vremena i duh naroda, prožimanja umetnosti, razvoj umetničke svesti, te shvatanja o smeni vrednosti, nacionalnom stilu, tipologija uticaja i kauzalni metod postaju sredstva za funkcionalizaciju suštinski iste paradigme razvoja i njeno fiksiranje u konkretni oblik. U tako shvaćenom procesu, književna istorija devetnaestog stoleća iscrpljuje se u pokušajima da ostvari paradigmu razvoja pomoću različitih sredstava, a validnost odabranih kriterija opravdava se celinom dela i činjeničnim, pozitivnim osnovama zaključaka ka kojim se istorija kreće. Sa druge strane, ukoliko samu problematiku shvatimo u užem značenju, kao svojevrsni promenljivi „sistem“ dela (Lešić, 1985: 193-197) nad kojim treba uspostaviti poredak, paradigma razvoja dobija svoj savremeniji oblik.

Druga važna paradigma razumevanja istorije je ideja cikličnog toka. Prema ovoj koncepciji, ne postoje evolutivni razvoj, progres, niti organicistička usložnjavanja umetničkih oblika od jednostavnijih ka složenijim, već večito vraćanje istog, neprekidno ponavljanje istih ili sličnih (tipoloških) kategorija. Ovakvo stanovište nalazimo u najrazličitijim izvorima, mada je znatno manje prisutno kao paradigma prilikom pisanja književnih istorija. Rudimentarni oblik ideje nalazimo još kod pesnika Plejade, u konceptu sukoba između starih i modernih. Ideja „starih i novih“ ostala je jedan od osnovnih primera ovakvog razumevanja književne istorije, mada se ,smena generacija“ može iskoristiti kao jedan od elemenata za strukturiranje paradigme razvoja. U novija vremena, slična cikličnost se može prepoznati u Velflinovim (Wölfflin) smenama baroknog i renesansnog stila, različitim „teorijama talasa“ - recimo, u teoriji klatna Luja Kazamjana (Cazamian) - te na kraju i kod meta-istoričara poput Alfreda Tojnbija (Toynbee). Elemente ove paradigme možemo naći i u teoriji književne evolucije ruskih formalista, koja u svom najrazvijenijem obliku kod Tinjanova (Тыня́нов) i dalje zadržava fundamentalno ciklični mehanizam odnosa između periferije i centra (Петковић, 1986: 93-103).

Ukoliko se za trenutak fokusiramo na osnovnu problematiku istinitosti književnosti u klasičnoj književnoj istoriji, možemo da vidimo da se književni proces u sklopu dve spomenute paradigme tokom devetnaestog stoleća shvatao na nekoliko načina. Delo je obuhvatalo više konkurentnih

tematici pristupio istorijsko-genetički, trudeći se da isprati tok ideja onako kako su se pojavljivale u istorijskom kretanju. Naš pristup je tipološki, i utoliko bliži Uligovom, jer se interesuje najpre za praktične probleme koji utiču na pisanje književne istorije. 
nizova (ličnost autora, imaginacija, forma dela, uticaji, itd.) koji su sačinjavali njegov horizont, što nužno pretpostavlja da čak i u najtvrđim pozitivističkim istorijama, književnost nikada nije bila samo ogledalo stvarnosti i nikada nije bila puki supstrat drugog niza (Lešić, 1985: 177-180). Ono što je zajednička platforma devetnaestovekovnih pristupa književnoj istoriji jeste vera u spoznajnu mogućnost istorije da spozna samu istinu književnosti. Shodno tome, i empirističke i nominalističke struje pozitivne književne istorije su istinitost književnosti izvodile iz teorije korespondencije, često je zasnivajući na etičkom ili epistemološkom imperativu, kakav je slučaj kod Sent-Beva (Sainte-Beuve) ili Ipolita Tena (Taine). Teorija korespondencije, koja podrazumeva da je ,istinito ono što odgovara stvarnosti“" (Kvas, 2011: 11), ne može se primeniti bez ostatka, jer se odgovarajuća korespondencija nije uvek uspostavljala između stvarnosti i književnosti (što bi odgovaralo mimetičkom modelu istinitosti), već i između činjenica kao pozitivnih kategorija i ponuđenih vrednosnih sudova. ${ }^{5}$ U slučaju romantičarske i duhovnoistorijske koncepcije književne istorije, situacija je još složenija. Možemo reći da prevladava model evidencije, koji podrazumeva autonomnost suda kao nosioca istine (Kvas, 2011: 21), a umetnost smatra neodvojivom od iskustva. Književnoistorijska praksa, međutim, kolebala se između evidencije i korespondencije, čime je narušen integritet autonomnog značenja, što je obično vodilo do toga da se istina književnosti u prvom slučaju shvatala putem modela autentičnosti, gde je iskrenost autora predstavljala garant istinitosti, ili preko figurativnog modela, koji je imao potencijal da „fikcijom redefiniše istinu stvarnosti“ (Kvas, 2011: 51), dok se u drugom slučaju izvodila iz nekakvog spoljašnjeg kriterija. ${ }^{6}$

$5 \quad$ U tom smislu, recimo, Tenov radikalni empirizam i podela na rasu, sredinu i trenutak, sugerišu dublji i slojevitiji kontekst razumevanja istine umetnosti. Iako ne sasvim autonomna, književnost ipak ostvaruje svoju istinu u saglasju između objektivnih činjenica i individualnih dela - ne radi se, dakle, o „svođenju“ umetnosti na ponuđene kategorije, već o pokušaju da se paradigma razvoja ostvari u saglasnosti sa modelom za koji se verovalo da je način dolaženja do istine književnosti.

6 Na primer, pojedini nemački književni istoričari imali su tendenciju da obrađuju odnos između individualnog pesničkog sopstva i odlika nacionalnog duha. To je podrazumevalo da se značenje izvodilo na dva načina. Prvi se rukovodio unutrašnjom prirodom individualnog pesničkog sopstva koje je formiralo epohu, oličenog u portretu koji je pružio istoričar. Varijacije tog postupka srećemo kod Rudolfa fon Gotšala (Gottschall), Karla Fijetora (Viëtor) i Oskara Valcela (Walzel). Drugi način uspostavljao je saglasje između 
Skicirane paradigme klasične književne istorije mogu se dopuniti još nekim istorijskim primerima, od kojih je verovatno najistaknutija paradigma koju bismo, uslovno, mogli nazvati funkcionalnom, i koja podrazumeva one književne istorije koje svoj predmet vide kao ispunjenje ili funkciju nečeg drugog. Najupadljiviji primer takvih tendencija svakako bi bile sociološke ili marksistički intonirane istorije književnosti. No, vredi istaći da marksistička književna istorija takođe počiva na istorijski aktuelnim pretpostavkama istinitosti. Ona romantičarski utemeljenom nagonu ka rekonstrukciji razvoja individualnog pesničkog genija suprotstavlja vlastite univerzalije koje prevazilaze nacionalno, književno, pa i umetničko. To, međutim, ne menja činjenicu da ni marksistička istorija književnosti ne može da se utemelji bez vlastitog shvatanja istorijskog procesa, koji je u njihovom slučaju mimetički. Lukačeve (Lukács) analize istorijskog romana - na stranu to slažemo li se sa njegovim zaključcima ili ne - najčešće se temelje na premisama klasne analize. Sociološka shvatanja društvenih kretanja rukovode izborom romana koji se analiziraju. Tok koji se pritom uspostavlja, od odabira građe do zaključaka koji se izvode - narativ koji Lukač razvija - uslovljen je marksističkom hipotezom o uslovljenosti društvenih (duhovnih) proizvoda od materijalnih uslova. Na taj način, iz Lukačeve perspektive, istorija romana postaje riznica primera za odslikavanje društvenih tokova.

\section{II}

\section{Teorijski temelji nove paradigme književne istorije}

Lukačevo mesto među istoričarima književnosti predstavlja primer relativizma koji već dugo nagriza istoriju književnosti, i naglašava da u problematici shvatanja istine (književnosti) retko postoji jednoznačna situacija. Neslaganje povodom validnosti njegovih zaključaka počiva na problemu shvatanja dominante njegovog istraživanja. Rečju, od odgovora

trajnih odlika duha naroda ili neke druge univerzalne kategorije koja je upravljala stvaralaštvom pesnika, kao u slučaju Georga Gervinusa (Gervinus), Julijana Šmita (Schmidt), Vilhelma Šerera (Scherer). Dok je u prvom slučaju posredi model autentičnosti, u drugom se radi o mimetičkom modelu, koji podređuje pesništvo razvoju nacije. Razume se, ponuđeni primeri samo su grube tipološke odrednice. Za više o problemima romantičarske i duhovnoistorijske književne istorije videti studiju Pesnik i književna istorija, o prikazivanju pesnika u nemačkim istorijama književnosti (Лома, 1994). 
na pitanje da li je Lukaču bitniji (sociološki intoniran) razvoj romana, ili pak društveni mehanizam čiji je odraz umetnost, zavisi i to kako ćemo ga vrednovati i čitati. Često same materijalističke istorije nisu ni razmatrane, nekmoli prihvaćene među onima koji su njihove početne pretpostavke - osnovu na kojoj su gradili shvatanje istine književnosti - smatrali netačnim. Otud ne čudi što se ni sama ideja uspostavljanja narativa kao najnovije paradigme istorije književnosti ne može odvojiti od problema relativizma, kako na planu same umetničke književnosti, tako ni na planu književne istorije. Štaviše, proširenje narativnosti na elemente javnog diskursa, pa i kulture u celini, omogućilo je da se sa tog aspekta i istorija književnosti dovede u pitanje. U tom smislu Bart i Vajt, predstavljaju samo dve klasične figure u procesu osporavanja književne istorije.

Nasuprot dosad razmatranim primerima, savremena shvatanja književne istorije počivaju na paradigmi narativa i tako čine epohalni interpretativni skok. Gotovo svi savremeni pristupi istoriji, bili oni sami istorijski ili teorijski zasnovani, tumače osnovu istorije kao konstrukciju ili uspostavljanje narativa. ${ }^{7}$ Daleko od Eliotovog (Eliot) ,idealnog poretka“, pitanja koja sobom povlači ideja narativnosti sasvim su druge prirode. Kao prevashodno teorijski fenomen, paradigma sadrži elemente koji su primenljivi i na pojmove klasične istorije književnosti - pripovedanje, tačka gledišta, motivacija, elementi ,zapleta“, vreme i događaji se mogu, uz određenu rezervu, prilagoditi pojmovima razvoja, unutrašnjeg kontinuiteta, periodizacije, selekcije građe, itd. Ono što je radikalno drugačije u modernom pristupu književnoj istoriji jeste sam podrazumevani kontekst narativa, koji konotira fiktivnu prirodu istorijskog znanja.

Rolan Bart će se, na različite načine, kroz čitavo svoje stvaralaštvo vraćati na ideju književne istorije, uvek iznova preispitujući mogućnost postojanja klasične istorije književnosti. Sažeto, Bartovo shvatanje, izloženo u više različitih eseja o problemu istorije, glasilo bi ovako: opisivanje i usredsređivanje pažnje na materijalne okvire stvaranja u klasičnoj istoriji služi što boljem opisivanju autorske figure - a u drugim istorijskim

$7 \quad$ Iza ovog trenda, pored već spominjanih Barta i Vajta, stoje i Bodrijar (Baudrillard) i Fuko (Foucault), kao veliki ,proroci“ novog shvatanja istorije, te Riker (Ricoeur), čija su istraživanja vremena i priče možda najefektnije predstavila fenomen narativa kao problem diskursa kulture. Njima se može pridodati i praksa kritičara poput Moretija i škole novog istorizma (New Historicism), nakon čega se dobija mozaička slika teorijske i praktične osnove nove paradigme u razumevanju istorije. Ovi teoretičari se često spominju povodom koncepta ,postmoderne istorije“ (Jenkins, 1997). 
granama povlašćeno mesto nema autor, već događaj - što samo po sebi sužava umesto što širi perspektivu istorijskog saznanja. Ključni problem je i to što istorije književnosti i nisu drugo do istorije ideje o književnosti, a većina istorija, koje su zapravo samo tomovi pojedinačnih istraživanja, to sasvim zaobilazi. U konstelaciji ovakvog shvatanja, za Barta jedina moguća istorija književnosti može biti „sociološka“, to jest istorija institucija „,na razini književnih funkcija“ (Bart, 1971: 152). Ovakva vizija književne istorije kao da iznutra rasvetljava Bartovu čuvenu tezu o „smrti autora“ ukoliko je književna istorija nesvesna ili neuspela istorija institucija, onda čak i pokušaj istorijskog fiksiranja figure autora pre „upisuje“ sama dela u istoriju nego što afirmiše pojedinačnu autorsku figuru. Tako autor postaje fantom koji zamenjuje i kompenzuje institucionalnu prirodu pravog istorijskog domena, što dovodi do toga da autori koje istorije opisuju nemaju veze sa stvarnošću. Autorsko sopstvo postaje isključiv predmet bartovske voljno paradoksalne kritike.

No, prava suština Bartovog razumevanja istorijskog može se skicirati preko njegovog ispitivanja mogućnosti fiksiranja istorijskog narativa. Polazeći od bahtinovske filozofije jezika (u kojoj kontekstom omeđen izraz igra ključnu ulogu), i paradoksalno je kombinujući sa Jakobsonovom podelom jezičkih registara i opštim pretpostavkama strukturalne lingvistike, Bart je u eseju Diskurs istorije (Le discours de l'histoire) pokušao da opiše probleme i paradokse epistemološke pozicije istoričara. Bartovo čitanje te pozicije nalikuje mitologizaciji samog procesa, ili, bartovski rečeno, čitanju strukture mita. Time što je postavio pitanje kako se iskaz fiksira u govorni čin, pokušao je da semiotički odredi značajne tačke u dotad neomeđenom prostoru pred-narativne svesti samog istoričara i gotovog teksta njegove istorije. Štaviše, to područje pokušao je da ojača stanovištem da istorija, pa i njen diskurs, uvek označavaju nešto izvan njih samih. Za Barta nijedna istoričareva odluka nije jednoznačna - reklo bi se da svaka ima barem jednu nepredviđenu posledicu, a čvorišne tačke njegove analize daju se podeliti u dve grupe - na one elemente koji se tiču organizacije toka istorije, i one koji se tiču figure autora. Istorija počinje ili invokacijom ili Predgovorom, kao govorom pre početka istorije, što je u Bartovoj vizuri peritekstualni dodatak koji inauguriše njenu dvostruku prirodu, jer dozvoljava istoričaru da tok koji sledi unapred izmesti i postavi prema vlastitoj subjektivnosti, sopstvenom vremenu, ili nekoj drugoj pojavi (Barthes, 1986a: 130). Vremenski tok istorije meandrira, linearno vreme konstantno 
se urušava, što uvodi prisećanje ovog početnog paradoksa, i čitalac sam nikada ne može da ostane u kontinuitetu sa „vremenom istorije“ koja se piše.

Potrebno je istaći da već na ovom koraku Bart pritajeno sa istoričarem postupa kao sa fikcionim činiocem u okviru diskursa. Ne samo da istoričar na kraju nije puki pošiljalac jezičke poruke, već je (u najboljem slučaju) udvojena persona - on konstruiše svoju unutartekstualnu sliku i putem ,referencijalne iluzije“" (Barthes, 1986a: 132) pokušava da čitaoce ubedi da ne govori on, već sam diskurs. Za Barta, pojmovi koje pojedini istoričari koriste kao čvorišta svojih istorija (navodi se, recimo pojam zavere kod Makijavelija) ne izviru ni iz građe niti iz prirode materije koja se obrađuje, već iz karaktera istoričara samih - oni su, dakle, proizvoljni. Tako se diskurs istorije ostvaruje u paradoksu između glasa istoričara i (lažnih) glasova kojim on dopušta da progovore. Pozitivistička istorija, sa svojim pozitivnim narativima (to jest, narativima koji ne poznaju negaciju, jer govore o onome što je bilo, a ne onom što se nije dogodilo) postaje ,šizofrena“" (Barthes, 1986a: 135) u svojoj epistemološkoj suspenziji „,pravog“ govornog čina.

Paradoks pozicije istoričara se, dakle, prenosi i na samu istoriju, pa se „objektivni“" sloj teksta nadopunjuje filozofijom istorije koja stoji iza njega. No, umesto da se takva situacija razume kao temelj istorije, ona postaje početna tačka njene razgradnje. Istorija se pretvara $\mathrm{u}$,imaginativnu elaboraciju“ (Barthes, 1986a: 138): isprva se označeno izdvaja iz diskursa, ali se brzo utapa u označitelja. Diskurs istorije onda postaje mašinerija za simulaciju stabilnog značenja. „Stvarnost“" postaje nedefinisano označeno, pa ispada da se i odbrane istorije putem argumenta „tako se zaista dogodilo" zasnivaju na tautologiji. Čak i prikriveni sukob između Diskursa i Stvarnosti predstavlja samo istorijski uslovljenu iluziju. „Stvarno“ za Barta predstavlja samo jedan od istorijskih modusa, kao i „moguće“, „živoliko“. U konačnici, „efekat stvarnosti“" nije ništa drugo do način da se i u proces istorijskog označavanja uvede problem iterabilnosti jezičkog znaka. Čak i onda kada je istorija najbliža denotaciji pojave, značenju stvarnog, efekat stvarnosti ga pretvara u označeno nekakve konotacije (Barthes, 1986b: 147-148). Praktično, to znači da je diskurs istorije, pa samim tim i istorijsko saznanje uvek izvedenica koja doseže do druge izvedenice. Istorija ništa ne govori o stvarnom, već putem jezičkih „glosa“ upućuje na proces sopstvenog uobličenja.

No, šta za književnu istoriju znači oduzimanje njene epistemološke osnove, nego oduzimanje svakog prava da govori istinu (naučnu, intimnu - svejedno) o književnosti? Istoriji dostupna stvarnost je uvek samo deo 
diskursa istorije, koji unapred predviđa, definiše i upućuje na dozvoljene mogućnosti u okviru mehanizma. Bartova analiza otkriva radikalizovano razumevanje istorijskog procesa iza kog ipak stoji deterministička vizija stvarnosti posredovana prikrivenom marksističkom dijalektikom. Opet sasvim bartovski, njegovo razumevanje odnosa između stvarnosti i istorije gotovo da je analogno njegovom shvatanju odnosa između pisanja i Književnosti. Štaviše, radikalni relativizam koji Bart posledično pripisuje suštini istorijske spoznaje stvarnosti i ne može biti istorija, već samo bartovski shvaćena Istorija kao institucija i ideologija. Analizom komunikativnog niza, Bart je narativnu paradigmu književne istorije okrenuo protiv nje same, radikalizujući svaki pokušaj da se dopre do smisla, na teorijskoj ravni onemogućavajući istoriji ikakav pristup smislu, pa čak i činjenicama. Čak i redukovana na događajnost, na puki niz sekvenci, istorija ne uspeva u doba modernosti, jer počiva na priznavanju „distance“ između čina i diskursa, kako bi njime ovladala (Barthes, 1986c: 149-150). Diskurs istorije tako postaje veliki mehanizam fundamentalno nesposoban da do istine dođe, opterećen idejom „stvarnog“ koja je ideološki posredovana.

\section{III}

\section{Književnoistorijski metod Franka Moretija}

Mesto Franka Moretija kao književnog istoričara interesantno je utoliko što se on ne može svrstati među tipične postmoderne ili radikalne protivnike književne istorije, pa čak ni među pobornike narativne paradigme. Nasuprot njima, on naizgled baštini ideju objektivnog i naučnog pristupa književnosti, u skladu sa rigoroznim istraživanjima i projektima koji stoje iza njegovih knjiga. Ipak, svaka sledeća knjiga i svaka nova tvrdnja koju iznese uvek izaziva nove kontroverze, a izvor toga svakako je barem delimično sam Moreti, koji ne čini ništa kako bi zabunu umanjio. U pokušaju da ocrtamo ono što je karakteristično za njegov postupak, moraćemo da se poslužimo različitim izvorima, raznovrsnim primerima, i velikim stepenom rekonstrukcije. Moreti do danas nije napisao vlastiti credo i njegova stanovišta razasuta su po člancima, pojedinim poglavljima njegovih knjiga i reakcijama na kritičke prikaze.

Moretijeva knjiga Grafikoni, mape, stabla (Graphs, Maps, Trees) nosi podnaslov Apstraktni modeli za književnu istoriju i utoliko predstavlja 
dobar početak. U njoj autor izlaže svoju zamisao da zasnuje „racionalniji model književne istorije" kao naučni metod koji bi proučavao nove probleme vezane za književnost (Moretti, 2007: 5). Model je racionalniji utoliko što pokušava da reši novi naučni problem: da nekako uključi nepregledni broj knjiga koje su ostale nepročitane. Predstavlja model, jer sistem mapa, grafika i stabala treba da posluži kao ideja koja se može primeniti na različite forme, periode, kulture, itd. Na obe ove tačke Moreti se osvrtao i ranije, govoreći o problemu ,velikog nepročitanog“" u svojim esejima $\mathrm{Na}$ gađanja o svetskoj književnosti (Conjectures on World Literature) i Klanica književnosti (The Slaughterhouse of Literature). Moretijev načelni stav mogao bi se sažeti na sledeći način: postojeći modeli književne istorije nisu reprezentativni, jer se zasnivaju na kanonskom uzorku koji je manji od jednog postotka sveukupnog broja knjiga. Sama metodologija pomnog čitanja ono je što nasilno sužava korpus čitljivog, i čini da ceo proces bude implicitno nesvestan periferije književnog sistema. U doba svetske književnosti - a Moreti pod svetskom književnošću pre podrazumeva globalnu književnost nego li geteovski ideal koji spominje - neophodno je radikalno proširiti teorijsku sliku i izmeniti način dolaženja do proklamovanog idealnog cilja Marka Bloha (Bloch), pa i same književne istorije: „čitav život analize za jedan dan sinteze“"8 (Moretti, 2013b: 47). Čuvena sintagma „čitanje na daljinu“ zapravo podrazumeva upravo to - oslanjanje na veliki broj čitanja iz druge ruke kako bi se postigla smislena i duboka sinteza koju ne bi bilo moguće ostvariti na drugi način.

Iako ovakvo stanovište koketira sa digitalnom humanistikom jer koristi prednosti baza podataka i digitalnih arhiva, ne sme se zaboraviti da je Moretijev prevashodni izazov upućen najpre književnoj istoriji, to jest ka prevazilaženju njene poslednje metodološke krize. Naime, sinteza kojoj se Moreti nada privlačna je zbog toga što naizgled apeluje na obe strane istorijskog jaza. On podjednako računa na skeptike - jer koristi metode drugih društvenih nauka, kao i savremene književne teorije koje odgovaraju na Bartovu aporiju - i na pobornike klasične istorije, kojima nudi dugo traženu sintezu kao konačni cilj čitavog poduhvata. Moretijev grupni rad izbegava stigmu pristrasnosti koju sobom nosi perspektiva jednog auto-

8 Svi citati prema izvorima na engleskom jeziku dati su u našem prevodu. Pošto u najvećem broju slučajeva prevod na srpski ne postoji, originalni termini i odlomci citata nisu navođeni i u originalu, kako tekst ne bi bio opterećen prevelikim brojem fusnota. Kurzivi u citatima preuzeti su iz originala, a podvlačenja predstavljaju naše isticanje. 
ra, istovremeno učvršćujući ideju nepristrasnog i objektivnog sintetisanja najrazličitijih pojava. Još važnije, izbegava i stigmu uobičajenog komitetskog, „kabinetskog“ pisanja istorija koje se mahom svode na parcijalne doprinose specijalista, bez ikakve vrhovne ideje vodilje. ${ }^{9}$

Prva tačka spomenutog metoda odnosi se na formulisanje teme, i u tome mu pomažu grafikoni, kao najapstraktniji odrazi različitih kretanja ekonomskih, socijalnih, književnih, itd. Na početku je neophodno pronaći odgovarajuću „morfološku tačku“ (Moretti, 2007: 25), koja će omogućiti dalju kvantifikaciju. Uzevši za primer roman, i oslanjajući se na postojeći korpus pozitivnih istraživanja diljem sveta, Moreti je ponudio grafikone koji ukazuju na ritam produkcije, prodaje, i drugih elemenata vezanih za stvaranje romana u nekoliko različitih sredina. $\mathrm{Na}$ osnovu tih podataka, suzio je svoj napor na ritam smenjivanja romanesknih žanrova u Britaniji, u periodu od 1740-1900. Na osnovu grafikona je uvideo da se žanrovi javljaju u grupama i traju od 10-25 godina, kao i da se simultano smenjuju dominantni muški i ženski pisci. Sledeće oruđe u istraživanju jeste formiranje mapa. Moretijeve mape ne moraju nužno biti istorijske karte istorijskih romana, već mogu predstavljati sistem tačaka u imaginativnom prostoru više romana, i to zbog često velikog značaja koji odnos između različitih tačaka može imati, mnogo pre nego značaj pojedinih konkretnih lokacija. U Moretijevom primeru, recimo, najveći broj pariskih romana iz spomenutog perioda smešta zaljubljene parove na suprotne strane reke Sene (Moretti, 2007: 55). Na isti način, mape industrijalizacije Britanije ili karte zaselaka ukazuju na prostorne i imaginativne veze u književnim delima tog perioda koje konkretizuju pojedine motive. Mape pomažu u preosmišljavanju odnosa, rasvetljavaju formalne i narativne odlike konkretnih dela. Zato mape uz grafikone predstavljaju osnovno sredstvo kojim se vrši prvobitno obuhvatanje i selekcija same građe. Konačno, pristupa se skiciranju morfoloških stabala pojave koja se izučava. Za Moretija, stabla predstavljaju rešenje večitog metodološkog pitanja odnosa između istorije formi i istorije književnih dela. Stabla otkrivaju „predmete znanja“

9 Razume se da govoreći o Moretijevom teorijskom i metodološkom radu, ne raspolažemo uvek sa valjanim i reprezentativnim rezultatima. Recimo, petotomna antologija koju je Moreti uredio u periodu od 2001-2003, naslovljena Roman (Il romanzo), predstavlja tipičnu vrstu istorijske hrestomatije, rascepkane na potkategorije sa prilozima specijalista datih oblasti. Uprkos tome što su mnogi prilozi inspirisani Moretijevim radom, ta hrestomatija je ona vrsta istorijskog rada koju bi nekom drugom prilikom sam Moreti najverovatnije kritikovao. 
(Moretti, 2007: 76) književne istorije. Stabla su mikroskopija formalnih odlika tekstova, a elementi takve analize ukazuju na makrostrukturne karakteristike neke pojave. Razvoj i skiciranje stabala otkriva kvalitativnu razliku između tekstova i nadoknađuju hladni, panoramski pogled grafikona i mapa. Moretijeva nada je da će kombinacijom ovih elemenata moći da kvantifikuje književne pojave širokog spektra, te da pruži širinu koja će dati rezultat dubinskih analiza.

Ono što se može zaključiti na osnovu ovakve postavke jeste da se vrednost književnih dela izvodi iz ideje reprezentativnosti. Za Moretija, očito, kanon predstavlja problematično suženje književnosti i u tom kontekstu nijedna prethodna istorija nije adekvatna. Sam postupak selekcije i organizacije predstavlja vrstu falsifikata. Kao i Bart, i Moreti u klasičnoj istoriji vidi samo privid smisla, privid značenja, dopisanu vrednost. Za razliku od Barta, italijanski istoričar odbija da na osnovu toga zaključi kako je čitav poduhvat neuspeo. Pokušavajući da kvantifikuje književnost, on pokušava da istakne kako je istorijsko mišljenje neophodno, ali ne u onim okvirima i pod onim uslovima u kojima je to činjeno ranije. Drugim rečima, kada se svedu računi, prethodne istorije govore istinu o književnosti samo do tačke vlastitog ukusa, koji je opet proizvod istorije. Objektivno značenje književnosti, stoga, ne može biti posredovano bilo kakvim činom personalne investicije, nikakvom vrstom hermeneutičkog kruga. Na fonu ovakvog metodološkog stava pitanje smisla književnosti postaje težište čitavog postupka, tačnije, kako se poima značenje književnih dela?

Mape, grafikoni i stabla predstavljaju samo sredstva, ilustracije šire poente. Ključni pojam Moretijevog istoriografskog metoda jeste postupak koji u jednom pamfletu naziva „operacionalizacija“. To je metoda kojom se vrši ,izgradnja mosta između koncepata i merenja, a potom i sveta... od koncepata književne teorije, kroz proces nekakve kvantifikacije, sve do književnih tekstova“" (Moretti, 2013c: 1). U nastavku svog objašnjenja, Moreti navodi koncept narativnog prostora u teoriji Aleksa Voloha (Woloch), koja se zasniva na ideji da količina informacija koje u tekstu dobijamo o pojedinim likovima ima interpretativni značaj. Važna razlika počiva u tome što je Moreti pošao od pretpostavke da se narativni prostor dodeljen liku može izmeriti putem tekstualne reprezentacije, koja se kvantifikuje uz pomoć broja utrošenih reči u celokupnom tekstu, ili putem izgradnje ,mreže" odnosa različitih likova u (dramskom) zapletu. Naravno, Moreti veruje da ovakav postupak daje težinu prethodno (proizvoljno?) odabranim kon- 
ceptima. ${ }^{10}$ Odavno prisutne književnoteorijske koncepcije kombinuju se sa sociološkim, lingvističkim, istorijskim, filozofskim i drugim analizama kako bi se ostvarila koherentna interpretacija. Pritom je od sekundarnog značaja šta se konkretno koristi, dokle god je princip kvantitativan, a rezultat dovoljno problematičan. Konačni bilans operacionalizacije mora da iznedri odgovarajući središnji problem, motiv, temu, rod, žanr, ili slično, koji će podstaći dalju kvantitativnu i istorijsku analizu. Ta analiza opravdava se potonjim rezultatima - u svom najreprezentativnijem vidu, otkrića bi trebalo da ponude dotad nepostojeći uvid u građu. To bi, uostalom, bilo sasvim u skladu sa Moretijevim poetičkim načelom. Njegov novi postupak trebalo bi da ,pruža podatke, ne interpretacije“" (Moretti, 2007: 9).

Međutim, Moretijevi funkcionalni pojmovi ipak su samo oruđa pomoću kojih se obrađuje književna građa. Osnovne odlike ovakvog postupka zapravo su sve samo ne nove, iako sadrže novu teorijsku potku koja ih naoko čini inovativnim. Ukoliko se za trenutak ponovo vratimo pozitivističkoj tradiciji, konkretno Ipolitu Tenu, naći ćemo veliku sličnost između njih. I jedan i drugi tumač bili su skloni kategorizacijama, generalizacijama, kao i vernosti pozitivnim činjenicama. Tenove kategorije, rasa, sredina i trenutak, modifikovane i osavremenjene, umnogome odgovaraju Moretijevim osnovnim metodološkim oruđima - mapama, grafikonima i stablima. Tamo gde je Ten video trajne odlike rase, specifične obrasce vezane za tradiciju neke nacionalne književnosti, ,genije naroda“ (Wellek, 1959: 7), Moreti pravi svoja stabla, koja konkretnu građu razlažu na uspešne evolutivne karakteristike. Tamo gde je Ten video uticaj klime, podneblja, uslove života i političke prilike, Moreti pravi mape koje pokazuju uticaj stvarne istorijske sredine na fiktivni svet umetničkog dela. Konačno, ono što je Ten smatrao momentom, specifičnim katalizatorom umetničkih dela, Moreti koristi kao materijal svojih grafikona, koji ukazuju na katalizator onoga što će se izučavati. Slično kao i Ten, ni Moreti nije sasvim vulgarizovao književnost sociologijom, pa ni teorijom književnosti, ali ujedno

10 U nastavku pamfleta, Moreti će „operacionalizovati“ Volohovu tezu tako što će analizirati tekstualni prostor Rasinove (Racine) Fedre. Fedra zaprema tačno 29\% teksta, Hipolit 21, Tesej 14, i tako dalje. Ovi podaci dalje se komplikuju, kada se uračuna broj razmenjenih reči, ko se kome obraća, itd. Na osnovu tih dijagrama, Moreti uviđa da je Fedra umnogome decentrirana, da se mnogo više obraća dadilji nego bilo kome drugom, a da nasuprot njoj, Tesej ima većeg dodira sa drugim likovima nego bilo koji drugi lik u drami. Moretijeva statistika će ustanoviti dva načelna kriterijuma tekstualne egzistencije: prvi, koji podrazumeva količinu teksta, i drugi, koji podrazumeva njegovu interaktivnost. 
nije uspeo da iznedri koherentan sistem i precizno definiše svoj aparat. Kao ni Ten u Istoriji engleske književnosti, Moreti ne pokušava da svojom teorijom matematički precizno eksplicira individualni genij, niti konkretna umetnička dela. Moreti ne smatra da stabla detektivske proze objašnjavaju Dojla (Doyle) isto koliko ni Ten nikada nije tvrdio da rasa sama po sebi može objasniti umetničko delo.

Ono što ostaje u slučajevima kada i jedan i drugi pristupe književnim delima jeste konstantni i uporni spoljašnji okvir koji služi kao trajno merilo, uz jednu ključnu razliku. Moretijeve mape i atlasi uvek su mape i atlasi stvarnog sveta, njegov kontekst je uvek socijalno-ekonomski kontekst, on se nikada neće interesovati za konkretnu umetničku individualizaciju oličenu u nekom književnom delu. Spoljašnji kontekst, klasni imperativ, ekonomska teorija, istorija ekonomije, predstavljaju validne teorijske dokaze koji mogu da usmere interpretaciju, ali u svemu tome nema traga od umetnika, književnosti, pa ni književnog života. Ono što je Tinjanov svojevremeno nazvao književnom činjenicom, za Moretija kao da se sasvim utapa u maglovite ideje publike, tržišta i forme. Književnost, dakako, ima spoznajnu vrednost, ona sadrži mnoštvo informacija, ali su one uvek uslovljene stvarnim svetom:

Nastupiti nakon nečeg, međutim, ne znači ponavljanje („odraz“) već postojećeg, nego upravo suprotno: podrazumeva rešavanje problema koje zadaje istorija. Svaka transformacija sobom nosi neku količinu etičkih prepreka, perceptivnih zabuna, ideoloških kontradikcija. Rečju, podrazumeva simboličko preopterećenje koje preti da destabilizuje društvenu koheziju i oteža egzistenciju pojedinaca. Književnost ublažava ovu tenziju. Rešavanje problema je pozvanje književnosti: ona čini egzistenciju razumljivijom i prihvatljivijom. (Moretti, 1996: 6)

Pojednostavljeno rečeno, moglo bi se reći da su činjenice za Moretija činjenice jedino ukoliko pripadaju stvarnom svetu ili se sa njim mogu dovesti u neposrednu vezu. Zato za Moretija nije važno skoro ništa sem korespondencije - njegova „materijalistička koncepcija forme“ (2007: 92) ne ostavlja prostora umetnosti kao umetnosti, to jest čisto umetničkom činu, već simulira epistemološki lanac kako bi pretendovao na istinitost.

Ovo se lako može ilustrovati putem analize Moretijevog razumevanja književnog tržišta kao neprikosnovenog arbitra sistema književnosti. 
Moreti ne tvrdi da se književna dela ističu nekim specifičnim umetničkim kvalitetima po sebi, već uvek predstavljaju odraz određenih formalnih, ideoloških ili kulturnih funkcija. Problem istorijskog tumačenja i počiva na činjenici da bez detaljnog i opširnog poređenja različitih dela nije moguće uvideti veze u sistemu književnosti. U prethodno spomenutom primeru Konana Dojla i njegovih kolega, Moreti je istakao da se indicije nalaze u detektivskoj prozi koja je ostala popularna (recimo, kod samog Dojla), a da ih nema u knjigama koje su danas zaboravljene. Shema značenja je sledeća: književno tržište ( $\mathrm{tj}$. najšira publika) pripisuje vrednost određenoj inovaciji koja vremenom postaje odlika žanra, pa samim tim postaje deo „dobrog“" stila i merilo vrednosti za potonje istoričare i potonju čitalačku publiku (Moretti, 1999: 42). Pritom, ta činjenica ne umanjuje vrednost samog postupka, inovativnost umetnika koji je to ,izmislio“, niti njegov doprinos istoriji pisane umetnosti, uprkos tome što ostaje nejasno odakle određene vrednosti, odakle tim vrednostima istorijska težina, i kakve su konkretne okolnosti njihovog uspeha. Čak i kad se ispostavi da shema indicija koju je nametnuo eliminiše čak i Dojla kao uspešnog stvaraoca, i kada postane jasno da je njegov uspeh uslovljen umećem (Marčetić, 2015: 135-136), Moreti neće odustati od sheme, postupka i istraživanja. Štaviše, čak i prekretničku pojavu u istoriji književnosti Moreti pripisuje nesvesnom odjeku u umetniku, kao u slučaju Dojla, ali i Džejn Ostin (Austin), koja u vihoru svog neznanja čini nešto novo, odražavajući u svojim romanima centralnu Moretijevu tezu o povezanosti romaneskne forme i ideje nacionalne države (Moretti, 1998: 14-15). Za Moretija ni istorijske sile oličene u romanima Dostojevskog (Достое́вский) nemaju vrednost po sebi, i nisu istinite zbog toga što se javljaju u romanu, već baš zato što imaju svoj geografski, prostorni korelat. ${ }^{11}$ Moreti je mogao da prihvati Dostojevskog u okviru svog istorijskog modela tek pošto je pronašao način da preko teksta potvrdi istorijski položaj Rusije. U suprotnom, Fjodor Mihailovič je prisutan samo kao još jedna jedinica u Moretijevom korpusu. Dostojevski je uspešan i reprezentativan utoliko što odražava objektivnu i

11 Razmotrimo sledeći citat: „U Rusiji, evropske ideje nisu samo ideje. To su „prestimulisane" sile koje ljude navode na delanje - i zločin ... Bazarov, Raskoljnjikov, Ivan Karamazov. Svi do jednog veliki likovi, veliki zbog svoje podvojenosti: zato što je sukob između Rusije i Zapada ušao u njihove umove i odjekuje u svakom egzaltiranom govoru, u svakom nepredvidivom postupku ... Eto primera gde geografija može, ako ne da odredi, a onda bar da podstakne morfološku promenu. (Moretti, 1998: 32) 
simboličku stvarnost Rusije svog vremena, a ne zato što je u pitanju izvanredan pisac. Štaviše, Moreti se nigde neće baviti vrednosnom procenom njegovih romana, već samo njihovim idejnim i semantičkim potencijalom.

Primeri kanonskih dela, koje klasične istorije navode kao predmete vrednosti, Moreti uglavnom navodi zbog široke upoznatosti čitalačke javnosti. Sama metodologija ne dozvoljava mu da ta velika dela tretira drukčije, osim ukoliko mu neki od kvantitativnih registara to ne sugeriše. Pozicija je umnogome suprotna formalističkoj, iako je inspirisana istim evolutivnim imperativom - dok je predstavnicima ruskog formalizma najvažnije bilo atipično, Moretija zanima serijalizovano, isto, ili preslikano u književnim delima, jer je to ono što kroji najveći deo književnosti (Moretti, 2013b: 180). Pošto takva dela ispunjavaju žanrove, ona nose najveći deo semantičkog obima. U Moretijevom kvantitativnom formalizmu evolucija umetničkih formi je uvek odraz društvenih kretanja, a umetnici samo prenosnici novih informacija, što je kritiku navelo da govore o Moretijevom „darvinističkom brikolažu“ (Winthrop-Young, 1999). Sličnom logikom, književnost nije nešto samosvojno, jedinstveno, neponovljivo, već samo produžetak jednog velikog evolutivnog lanca objektivnih okolnosti. Činjenica da je Moreti odabrao da se bavi razvojem romana devetnaestog stoleća čini mnogo u korist njegove metodologije i njegovom shvatanju prirode književnosti, jer se s pravom može reći da društvena stvarnost nikada nije bila u bližoj vezi sa umetničkim stvaralaštvom kao u tom periodu. Otud se nameće pitanje na koji način bi Moretijeva metodologija mogla da se primeni na, recimo, modernističku poeziju, i na koji način bi se uopšte zamislila kvantifikacija pozitivnih činjenica poezije koja ne bi bila radikalno udaljavanje od smisla poetskih tekstova.

Ukoliko se vratimo prvobitnim kriterijima za uspostavljanje književne istorije, situacija neće postati bolja. Moretijev rad u celini ima jasno definisan vremenski opseg. Njegov rad, takođe, poseduje jasno definisan kriterij za selekciju građe, što mu, nažalost, ne ide u prilog. Na prigovor kritike za naizgled proizvoljan odabir tekstova u jednom od svojih čuvenih eseja Stil, doo (Style, Inc.). Moreti je odgovorio da osnovu njegovog rada čine ,jedini podaci koji su u tom trenutku bili dostupni“ (2009: 147). Izbor tekstova (u pitanju su bila mahom britanska dela) nije, dakle, potekao ni od kakve koherentne ideje, već činjenicom da je postojao prethodno formiran korpus! Pošto je njegov rani rad prethodio osnivanju „književne laboratorije" (Literary Lab) na Stenford univerzitetu, postojala je nada da će nakon 
toga doći do izmene u samoj metodologiji. Kao što se može videti iz prethodno rečenog, Moreti je nastavio da rukuje korpusima na istovetan način, samo što mu je laboratorija omogućila da ih samostalno formira. Rečju, ostao je dosledan svojoj izvornoj metodologiji i zadržao isti odnos prema građi, koji gotovo potpuno zanemaruje ideju koherentnog poretka. On je dopustio da građa „sama“ diktira i upravlja načinom na koji će se formirati tok njegovog izlaganja, što je isticao kao teorijsko preimućstvo svoje metode. Ovaj propust u Moretijevom istoriografskom radu približava ga modernim shvatanjima istorije.

Kao što je Hejden Vajt s pravom istakao, narativni sklop moguće je prepoznati čak i u onim oblicima istorijskog diskursa koji formalno uopšte nije narativan, poput anala. Kako Vajt ističe, „mora biti priče, čim postoji zaplet" (1987: 13), a struktura i nizanje događaja koje srećemo u analima već predstavlja vrstu narativa u povoju. U tri svoje knjige koje se više ili manje direktno bave književnom interpretacijom - Bildungsroman u evropskoj kulturi (The Way of the World: the Bildungsroman in European Culture, 1987), Moderni ep (Modern Epic: The World System From Goethe to Gabriel García Márquez, 1996) i Buržuj (The Bourgeois: Between Literature and History, 2013) - Moreti pretenduje na zaključke istorije književnosti. To su pokušaji da se njegovo osnovno metodološko usmerenje preinači tako da bude u stanju da sintetizuje istorični i formalni pogled na sile koje su uticale na formaciju romana tokom devetnaestog stoleća. Šire gledano, ukoliko prihvatimo Vajtovo shvatanje, prema kojem istorije sačinjavaju ,podaci, teorijski koncepti kojima se objašnjavaju ti podaci, i narativna struktura putem koje se predstavljaju“(White, 1975: ix), možemo pokazati kako Moreti predstavlja primer istoričara koji pokušava da prevaziđe najnoviju istorijsku krizu. Privlačnost Moretijeve prezentacije znatno je veća od vrednosti njegovih zaključaka, ali je scijentistička metodologija osnovno oruđe kojim se ostvaruje njegov skriveni istorijski narativ. Kada pokušava da ocrta istoriju forme bildungsromana, on je prati preko više različitih konteksta - socijalni kontekst informiše umetničke postupke, koji utiču na male promene $u$ formi, te tako konstituišu žanrove i ispunjuju simboličke forme ideološkom sadržinom. Buržuj je, s druge strane tačka kristalizacije društvenih odnosa, ne samo kao materijal književnosti, već i kao politički agens koji je stvara. Književnost je deo globalnog geopolitičkog sistema, koji funkcioniše po mehanizmu „rastuće nejednakosti“ (Moretti, 2013b: 46), što znači da evolucija nije politički i društveno neutralna, i da promena u sistemu ima sistem- 
ske posledice koje se odražavaju na makroplanu. Ključne forme i obrasci radijalno se šire od velikih književnosti ka malim, od centra ka periferiji, a na kraju forma preseljena iz jedne sredine u drugu, proživljava morfološke promene na novom lokalu (transformacije stilskih registara, lokalni likovi, drukčiji prostor). Istorija književnosti postaje istorija društvene borbe za dominaciju, večita dijalektika odnosa naroda kroz prostore i vreme. Prateći devetnaesti vek, Moreti zapravo prati njegove periferne tokove - žanr romane i popularnu literaturu, kako bi pokazao relativnost postojećeg narativa književne istorije. Time posledično revalorizuje povlašćene, kanonizovane romaneskne forme i uzdiže periferne, dokazujući da je priroda sukoba u književnom i društvenom sistemu sveprisutna.

Od toga je sačinjen istorijski narativ, koji, iako mozaički, ipak postoji. Slika koju Moreti predstavlja čitaocima pokazuje da tržište kao siva eminencija rukovodi umetnicima, koji pored svih ekonomskih i društvenih sila kao da ni ne misle o lepoti, tradiciji, kulturi, savremenicima i prethodnicima. A sve i da misle, rekao bi Moreti, tržište svakako preinačuje ta njihova razmatranja i čini ih besmislenim. Vajt u svojoj Metaistoriji (Metahistory) sažima okvire istorijske imaginacije, dajući svakoj školi dominantni trop, modus, književni rod u čijem duhu se konstituiše zaplet, argumentaciju, ideologiju, i reprezentativnog filozofa i istoričara. Eksplozija istorijske misli u periodu 1830-1870, tvrdi Vajt, potiče od tri zasebne vrste „stvarnosti“ koje projektuju veliki istoričari (1975: 40), reagujući na krizu romantičarskog entuzijazma. Za nas je od značaja samo jedan niz: trop je metonimija, modus je redukcionizam, zaplet je tragički, argumentacija je mehanicistička, ideologija radikalna. Filozof je Marks (Marx), istoričar Tokvil (Tocqueville). Pogledamo li za trenutak Vajtovu ocenu Tokvila kao istoričara, videćemo da je umnogome primenljiva na Moretija:

Zato što je za njega bitak sam bio misterija, Tokvil nije svoju misao mogao da dovede do kontemplacije istorijske nauke, koju je naizgled predviđala njegova tipologija istorijskih fenomena. Ovaj nesvarljivi ostatak tajanstva sprečio ga je da konceptualizuje zakonitosti i pravila koja bi mu omogućila da se pozabavi činjenicom da se istorija sama naizgled raspada na međusobno isključive i repetitivne tipove društvenih fenomena. (White, 1975: 194)

Ovakav manir ključni je metodološki problem Moretijevih analiza. U pokušaju da odgovori na Bartov izazov i zasnuje „stvarnu“ istoriju 
književnosti, Moreti je podlegao zamci svoje suštinski nihilističke vizije književnog procesa. Samo pripisivanje značenja skoro je uvek ostavljeno nerešeno - Moreti veruje da su veze o kojima piše upadljive, neočekivane, i neosporne. Te veze, međutim, nisu neutralni korelat nasumične građe, već predstavljaju ,činjenice“ koje je on sam uočio kao interpretator, i kojima je sam pripisao određenu vrednost i značaj. Drugim rečima, Moreti takođe vrši odabir i selekciju građe u okviru svog istorijskog postupka, samo što to čini u okvirima (grafikoni, mape, atlasi, stabla) koji pružaju iluziju apsolutne nepristrasnosti. Moreti sam, birajući formalne karakteristike i prateći njihovu evoluciju, koristi isti (žanrovski, morfološki) sistem koji karakteriše istoriju i teoriju književnosti, te pokušava da proširi njihove granice drugim metodima, praveći se pritom da je taj metod neutralan zbog činjenice da se barata objektivno sakupljenom građom. Kako je jedan od njegovih kritičara primetio, „Moreti nije istoričar književnosti, on je istoričar koji se samo bavi književnošću“ (Winthrop-Young, 1999: 19). Čak i tamo gde postoje fundamentalne evolutivne razlike, koje, recimo, mogu biti uslovljene autohtonom književnom tradicijom, kao u slučaju Rusije, Moreti vidi korelat drukčijeg prostora a ne slučaj samosvojnog duhovnog razvoja.

Ako bi neko pitao Moretija veruje li u to da je književnost istinita, malo je verovatno da bi se tome usprotivio. Međutim, ostaje nejasno šta književnost znači u okviru njegovog istorijskog mehanizma. Ukoliko je tačno da je funkcija književnosti u smirivanju društvenih tenzija, to bi značilo da književnost čuva semantički potencijal jednog konkretnog istorijskog trenutka u kojem se ostvaruje, što neraskidivo vezuje vrednost književnosti za (istorijsku) stvarnost. Međutim, ne može se reći da Moreti zastupa ideju da književnost, pa ni književne forme, predstavljaju samo odraz stvarnosti. Pošto tumačeći književnost u suštini dolazimo do saznanja (ili do potvrde naših saznanja), to znači da književnost nosi određeno znanje o stvarnom svetu. Ipak, možda je bolje reći da književnost znači, nego da označava ili po svojoj prirodi nosi značenje. Iako su u pitanju nijanse, jasno je da za Moretija književnost označuje samo posledično, a ne prema sopstvenom unutrašnjem imperativu. Osvrnemo li se na čuvenu definiciju teorije odraza Todora Pavlova (Павлов) о „subjektivnom odrazu objektivne stvarnosti“" (Focht, 1974: 13), možemo da razumemo zašto se Moreti trudi da izbegne kruti redukcionizam podražavanja. Međutim, glavni problem sa stanovišta istorije književnosti počiva u tome što je Mo- 
reti jednostavno isključio subjektivni odraz kao kategoriju, u pokušaju da eliminiše rigidnost mimeze, a očuva čvrste hegelijanske racionalne okvire koje stoje u korenu istorijskog materijalizma. U svom tekstu Amuzija hegelijanstva, Ivan Foht (Focht) će sugerisati interesantnu paralelu. Pišući o problemima krutog racionalizma, primetiće da je u srži Hegelovog filozofskog modela izvesna iracionalnost vere $u$ racionalno, $\mathrm{i}$ da racionalna definicija duhovnog predstavlja ključni problem:

Da li bi se moglo to „duhovno polje“, ako postoji, smatrati nečim svjesnim? Tada je njegov cilj stalna izgradnja, a ono utjelovljuje - očito - univerzalnu energiju ... Iz te „energije duhovnog polja“" stvarala bi se materija u svom najjednostavnijem obliku i zatim se vezala u složene strukture. To duhovno polje moglo bi biti prostor. (Focht, 1974: 14)

Šire gledano, i veoma zaoštreno, moglo bi se tvrditi da i u slučaju Moretija kategorija prostora sasvim preuzima duhovno ontološko polje, te da je zbog toga nemoguće premostiti jaz između teorije evidencije, kategorije subjektivnog iskustva, i teorije korespondencije. Ukoliko, huserlovski gledano, postoji apsolutna podudarnost subjekta i objekta, postavlja se pitanje kako uopšte razlikovati književnost od stvarnosti. Smeštena između Moretijeve statistike i huserlijanske podudarnosti, književnost, dosežući apsolutnu istinu, gubi svaki smisao kao književnost, jer se ne može razgraditi niti razgranati autonomno. Ako se, pak, priklonimo Gadameru (Gadamer) i ideji umetnosti kao svedočenju istine, vraćamo se na subjektivno iskustvo koje Moreti sve vreme poriče. Moreti nigde ne daje za pravo da mislimo da je činjenica kojom se on bavi - da je forma romana u bitnome povezana sa društvom devetnaestog veka - stvar književnosti u celini. Otud, iako možemo tvrditi da se Moretijev rad zasniva na pretpostavkama korespondencije, to možemo učiniti samo sa velikom rezervom. Iako njegova metodologija ukazuje na potrebu za čvrstim i objektivnim uporištem kao fundamentom znanja, istinitost književnosti figurira u dva vida: ili kao korespondencija po mimetičkom modelu, na šta ukazuju njegova sistematična merenja i socio-ekonomska analiza, ili kao evidencija, makar ona bila redukovana.

Najveća praznina Moretijevog postupka počiva u sistematskom prećutkivanju i odbijanju da spomene ili objasni odnos njegovog mehanizma i subjektivne teorije saznanja. Iako možemo da tvrdimo da Moreti smatra da 
istinitost potiče od iskustva, to iskustvo uvek ostaje kolektivno, izdignuto iznad pojava konkretnih umetničkih dela. Njegova statistika predstavlja vrstu kolektivne epistemologije, u kojoj je književnost sasvim podređena, što na planu filozofije književne istorije prerasta u krupniji problem. Redovno propušta da čitaocima pruži vlastiti odgovor na ključna pitanja - da li smo mogli da dođemo do sličnih zaključaka o romanu XIX veka iz sasvim druge perspektive (recimo, hermeneutičke ili naratološke)? U kojoj meri baš njegov postupak dovodi do „ključnih“ rezultata? Još važnije, da li njegov postupak sam po sebi pruža najjače argumente u korist sopstvenih stanovišta? Ili još konkretnije, šta stabilizuje evoluciju formi kroz prostor i vreme, društva i pojave, ako ne individualno iskustvo? Šta garantuje inovaciju, ako ne pojedinci koji učestvuju u književnosti? Razume se, Moreti je potpuno svestan da merenja sama po sebi nemaju vrednost (2013c: 5), što je i osnovni razlog njegovim pokušajima da ih rasporedi na način koji će ukazivati na nekakve uzročno posledične veze, ali, koje, naposletku, nikako ne može da dokaže. Kao i većina modernih književnih istoričara, i Moreti priželjkuje alternativnu književnu istoriju koja bi došla do fundamentalnih novih otkrića, ali nije u stanju da ukaže na ključne korake na tom putu sa onom sigurnošću koja mu je potrebna.

Ova epistemološka praznina za posledicu ima prazninu književnosti, koja postaje vulgarizovani „nosač“ društvenog sadržaja, objektivni odraz subjektivne - tj. Moretijeve - stvarnosti. Iako smo na početku mogli da pretpostavimo da elementi narativne paradigme mogu imati ekvivalente u pojedinim kategorijama klasične istorije, kod Moretija su te kategorije neutralisane. Kao što smo već mogli da vidimo, ne postoji kategorija unutrašnjeg razvoja (dapače, ne postoji kategorija unutrašnjeg kao takvog), niti koherentni kriterij za selekciju građe. Ono što održava iluziju istorijskog toka je depersonalizovani narativ koji omogućuje čitaocu da veruje pročitanom. Jezik brojeva, matematike i evolucije čitaocima se vešto podastire kao istina, kao zatečeno stanje stvari, te mozaički, analistički gradi tačke zapleta. Međutim, važno je napomenuti da se pored kategorija klasične istorije neutrališe i relativizam narativnosti, što je po našem mišljenju glavni razlog za uspeh i popularnost Moretijevog metoda među pobornicima klasične istorije. Pošto narativna paradigma teži dekonstrukciji istorijskih ,priča“, ona po prirodi stvari fikcionalizuje istoriju. Međutim, time što osnovu informacija izmešta iz (isključivo) jezičke reprezentacije u kvantitativno polje, Moreti može da postigne efekat stvarnog bez otu- 
đenja. On pripoveda, ali kroz grafikone, mape i stabla, koji su njegova varijanta sveznajućeg pripovedača. Ključna razlika počiva u tome što se takav diskurs ne može razložiti u Bartovom maniru, jer je, na primer, 17\% tekstualnog prostora nekog književnog lika nepobitna činjenica korpusa. Zaplet čini pozornica sistema književnosti, a prikazuju se događaji relevantni samo za taj sistem. Moreti je pokušao da u diskurs istorije upiše vlastite ideološke stavove o književnosti, služeći se depersonalizovanom narativnom tehnikom, kako bi toj svojoj konstrukciji dao privid objektivnosti i stabilnog značenja. Iz ovog ugla, ne samo da ne možemo govoriti o korespondenciji, već ovaj izmenjeni narativni kontekst u Moretijevoj redakciji vodi samo u potpunu relativizaciju svakog (sa)znanja, uključujući, na kraju, čak i individualnu spoznaju aktuelne stvarnosti.

Posledice toga su zastrašujuće: ukoliko se ne slažemo sa Moretijevom tragičkom vizijom književnog tržišta, književnost, onakva kakvom je on opisuje, nema apsolutno nikakvu vrednost. Jedna kritičarka je primetila nešto slično, te je predložila istoriju knjiga kao idealni metod za premošćivanje jaza između pomnog čitanja i Moretijeve interpretacije statistike (Trumpener, 2009: 163). Iako to nije formulisala na isti način, ponudila je ideju prema kojoj istorija izdavaštva, institucija, kriterija i trendova može pružiti uvide u sile tj. odnose moći koje upravljaju književnošću. Mi bismo rekli - one sile koje utiču na prenos i transpoziciju istine od pojedinaca ka kolektivnoj imaginaciji - što Moretija zapravo interesuje. Međutim, čak ni ovakva blagonaklona dopuna ne uvodi novi sadržaj u koncepciju: društvo i dalje gotovo jednosmerno utiskuje svoj ideološki sadržaj u literaturu, a uzroci promena i dalje ostaju nepoznati. Da li je ovakva kritika preterana? Odgovor će zavisiti od preovlađujućeg metodološkog stava. Ukoliko ostanemo dosledni mimetičkoj komponenti gnoseološkog imperativa (što ni sam Moreti ne čini), izuzetno je važno odrediti precizan uzrok određene pojave, jer u tom slučaju uzročnik ima informativnu vrednost koju daruje čitavom sistemu i omogućuje dalje praćenje i evoluciju te nove činjenice kroz sve mene i okolnosti kroz koje takva pojava može proći. Sa druge strane, klasične istorije su pridavale veći značaj „činjenicama duha“, to jest onim uticajima i faktorima koji su činili pokretače, recimo, pesničke imaginacije i doprinele konstituisanju individualnog pesničkog genija. U prvom slučaju radi se o spoljašnjem uzročniku koji određuje odlike svih potonjih procesa, jer menja celokupni sistem. U drugom se radi o unutrašnjem uzročniku, koji može imati spoljašnji podsticaj, ali ipak neće 
sačinjavati suštinu pesničke ličnosti, koja će ga transformisati na jedinstven način. Moreti je primenom teorijskog aparata pokušao da koriguje preveliki determinizam i otvorenost spomenutih stanovišta, da bi svojom nedorečenošću zapao u nihilizam skoro totalnih razmera, i tako se izložio kritici obeju strana.

„Evo šta bi uporedna književnost mogla da bude, kada bi sebe shvatila prvo kao svetsku književnost, a onda i kao uporednu morfologiju“, piše Moreti (2007: 90). No, problem sa takvim postupkom počiva na vrednosti i značenju dobijenih rezultata. S jedne strane, Moreti obećava prevratnički, revolucionarni karakter svog inkluzivnog postupka. Sa druge strane, ideja udaljenog čitanja, uprkos tome što je svesna svih problema, ne odvaja se od klasične istorije. Iako Moreti tvrdi da ga kritičari nisu razumeli, ostaje činjenica da njegov novi postupak nije spasao od zaborava nijedno epohalno delo, niti je, pak spustio sa prestola neki kanonizovani roman. Nije doprineo većem i raznovrsnijem čitanju, i, najvažnije, nije destilovao nove fundamentalne principe književnog niza. Moretijev rad nije ostvario nijednu od svoje dve pretenzije: nije preovladao bartovsku aporiju narativnosti, i na kraju nije uspeo da se odmakne od kanona. Makar samo do tačke u kojoj se trudi da ga ignoriše, Moreti računa na kanon, i u stvari postavlja pitanje geneze naših stavova o književnosti, što je osnovna iskupljujuća odlika njegovog rada. U Zapadnom kanonu (The Western Canon), Harold Blum (Bloom) ponudio je jednu od svojih apodiktičkih definicija: „Kanon, to su Platon i Šekspir, to je slika pojedinca kako misli“ (1993: 35). Ukoliko nastavimo ponuđenu metaforu, Moretijev metod u svom najboljem dometu nudi moguć odgovor na pitanje koje su to sile, formalne, socijalne i morfološke, dovele do imaga Platona kao ideograma kanonske imaginacije. Nažalost, kao što je očigledno iz svega rečenog, vrednost tih opservacija je isključivo izvedena, a vrednosni sud trajno odložen, što znatno umanjuje čar celokupnog projekta. 


\section{LITERATURA:}

\section{Latinična:}

Bart, R. (1971). Istorija ili književnost. U R. Bart, Književnost, mitologija, semiologija (str. 143-162). Beograd: Nolit.

Barthes, R. (1986a). The Discourse of History. In The Rustle of Language (pp. 127-140). Oxford: Basil Blackwell.

Barthes, R. (1986b). The Reality Effect. In The Rustle of Language (pp. 141149). Oxford: Basil Blackwell.

Barthes, R. (1986c). Writing the Event. In The Rustle of Language (pp. 149-154). Oxford: Basil Blackwell.

Focht, I. (1974). Amuzija hegelijanstva. Polja, 186-187, str. 12-14. [on-line] Dostupno preko: http://polja.rs/wp-content/uploads/2016/07/selection3-15. pdf [20.10.2018.]

Jenkins, K. (ed.). (1997). The Postmodern History Reader. London: Routledge.

Kvas, K. (2011). Teorije istine i istina pesništva. U K. Kvas, Istina i poetika (str. 9-81). Novi Sad: Akademska knjiga.

Lešić, Z. (1985). Književnost i njena istorija. Sarajevo: Veselin Masleša.

Marčetić, A. (2015). Interdisciplinarna humanistika. U O novoj komparatistici (str. 107-140). Beograd: Službeni glasnik.

Moretti, F. (1987). The Way of the World: the Bildungsroman in European Culture. London: Verso.

Moretti, F. (1996). Modern Epic: The World System From Goethe to Gabriel García Márquez. London: Verso.

Moretti, F. (1998). Atlas of the European Novel 1800-1900. London: Verso.

Moretti, F. (1999). Structure, Change, and Survival: A Response to Winthrop-Young. Diacritics, 29(2), pp. 41-42.

Moretti, F. (2007). Graphs, Maps, Trees: Abstract Models for Literary History. London: Verso.

Moretti, F. (2009). Relatively Blunt. Critical Inquiry (36), pp. 172-174.

Moretti, F. (2013a). The Bourgeois: Between Literature and History. London: Verso.

Moretti, F. (2013b). Distant Reading. London: Verso.

Moretti, F. (2013c). "Operationalizing": or, the function of measurement in modern literary theory. Pamphlets of the Stanford Literary Lab, 6. [on-line] Dostupno preko: https://litlab.stanford.edu/LiteraryLabPamphlet6.pdf [20.10.2018.] 
Trumpener, K. (2009). Paratext and Genre System: A Response to Franco Moretti. Critical Inquiry (36), pp. 159-171.

Ulig, K. (2010). Teorija književne istorije. Preveli D. Maricki, i M. D. Stefanović. Beograd: Službeni glasnik.

Wellek, R. (1959). Hippolyte Taine's Literary Theory and Criticism. Criticism, 1(1), pp. 1-18.

White, H. (1975). Metahistory: The Historical Imagination in Nineteenth-Century Europe. Baltimore: Johns Hopkins University Press.

White, H. (1987). The Content of the Form: Narrative Discourse and Historical Representation. Baltimore: Johns Hopkins University Press.

Winthrop-Young, G. (1999). How the Mule Got Its Tale: Moretti's Darwinian Bricolage. Diacritics, 29(2), pp. 18-40.

\section{Ćirilična:}

Лома, М. (1994). Песник и књижевна истиорија. Сремски Карловци: Издавачка књижарница Зорана Стојановића.

Петковић, Н. (1986). Један осврт на формалистичко тумачење књижевног развоја и на његову разраду у савременој семиотици. У П. Палавестра

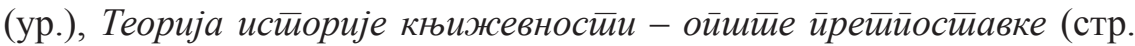
93-103). Београд: Српска академија наука и уметности. 


\title{
Stefan S. Alidini
}

\section{THE STATUS OF FICTIONAL TRUTH IN FRANCO MORETTI'S APPROACH TO LITERARY HISTORY}

\begin{abstract}
Summary
This paper is based on philosophical theories of truth (correspondence, coherence, evidence theories) and similar models of fictional truth (mimetic, ethical, epistemological, figurative models, and the model of authenticity) so as to analyse the theoretical and historiographical approach of Franco Moretti. The first part of the paper examines overarching theoretical problems of literary history and provides a framework for further analysis. A concise overview of the paradigms employed by the classical models of literary history (paradigms of development, function and cyclical history), as well as minimal preconditions for literary history, examines their attitude towards the concept of literary truth. The second part of the paper considers the latest, narrative paradigm of literary history through the work of representative poststructuralist theoreticians, Roland Barthes and Hayden White. From the chosen standpoint, it is clear that the narrative paradigm denies the possibility of reaching truth through history, and thereby relativizes the truthfulness of literature itself. The third part of the paper examines Moretti's work in the context of previously outlined paradigms. An analysis of his theoretical texts and practical work on a new literary history examines its relation to fictional truth. A closer look at his methodology reveals that it only appears to fulfil the minimal conditions for constituting literary history. Moretti adheres to the narrative paradigm insofar as he constructs a vision of literature that ultimately does not involve autonomous meaning or truth. Despite Moretti's attempt to resolve the methodological crisis of literary history, his quantitative formalism is only thinly veiled relativism.
\end{abstract}

Key words: Moretti; operationalization; literary history; literary theory; theory of literary history; truth theory; fictional truth; digital humanities; quantitative formalism; 